\title{
Trackball Device
}

National Cancer Institute

\section{Source}

National Cancer Institute. Trackball Device. NCI Thesaurus. Code C50224.

An electronic pointing device that incorporates a rotatable ball designed to detect motion of the ball in two dimensions. 